Proceedings of the International Symposium on Physics of Materials (ISPMA 14), September 10-15, 2017, Prague

\title{
Advanced Mechanical and Corrosion Properties of WE43 Alloy Prepared by Powder Metallurgy
}

\author{
D. DVORSKÝ $\bar{y}^{a, *}$, J. KuBÁSEK ${ }^{a}$, D. VOJTĚCH ${ }^{a}$ AND M. ČAVOJSKÝ ${ }^{b}$ \\ ${ }^{a}$ Department of Metals and Corrosion Engineering, University of Chemistry and Technology Prague, \\ Technická 5, 16628 Prague 6, Czech Republic \\ ${ }^{b}$ Institute of Materials and Machine Mechanics SAS, Slovak Academy of Sciences, \\ Dúbravská cesta 9, 84513 Bratislava, Slovak Republic
}

\begin{abstract}
Low density and good mechanical properties predetermine magnesium alloys for use in the automotive and aviation industries. Also, their biocompatibility and nontoxicity make these materials interesting for research in the field of biodegradable implants. Magnesium alloys with rare earth elements are the most advanced materials among magnesium alloys. These materials are characterized by good mechanical properties and corrosion resistance. Different methods can be used for the preparation of these materials. An interesting approach offers powder metallurgy method because final products are often characterized by improved mechanical and corrosion properties. This work is focused on the preparation of the $\mathrm{Mg}-\mathrm{Y}-\mathrm{Nd}-\mathrm{Zr}$ alloy by powder metallurgy method. Powders were milled in a ball-planetary mill for an increase of mechanical properties. Samples were prepared by extrusion of pressed powders at $400^{\circ} \mathrm{C}$. Spark plasma sintering was chosen as an alternative process for compacting of the powders. The microstructure of the final product was evaluated in terms of grain size and grain orientation. Mechanical and corrosion properties were investigated. Generally, final products were characterized by superior mechanical properties and also slightly lower corrosion rate if compared to the materials produced by standard methods.
\end{abstract}

DOI: 10.12693 /APhysPolA.134.748

PACS/topics: 81.20.Hy, 81.05.Bx, 61.66.Dk, 87.85.jc, 81.20.Ev

\section{Introduction}

Automotive and aviation industry are interested in light materials with good mechanical properties. Titanium, aluminum and magnesium alloys meet those requirements while magnesium is the lightest of those [1]. Magnesium is also used in medicine as a material for biodegradable implants. Such implants should gradually degrade in a body after fulfilling their function without the necessity of the second operation to remove them [2]. The most advanced magnesium alloy developed for the automotive industry is WE43, which contains $4 \mathrm{wt} \%$ of yttrium, $3 \mathrm{wt} \%$ of neodymium, $0.5 \mathrm{wt} \%$ of zirconium and other rare earth (RE) elements like dysprosium and gadolinium in a small amount [3]. Magnesium forms intermetallic phases with yttrium and neodymium which improves mechanical properties. Limited solubility of alloying elements in magnesium matrix allows this alloy to be thermally treated. The well-known heat treatment of this alloy consists of annealing the sample at $525^{\circ} \mathrm{C}$ for $8 \mathrm{~h}$ with consequent quenching in water (T4) and ageing at $250{ }^{\circ} \mathrm{C}$ for $16 \mathrm{~h} \mathrm{[4]}$. The solid solution is supersaturated after $\mathrm{T} 4$ as the eutectic and other less heat stable phases dissolve. Precipitates of $\beta^{\prime \prime}$ (orthorhombic, metastable phase), $\beta^{\prime}$ (D019, metastable phase), and $\beta$ emerge during the ageing process [5]. Average values of tensile yield

*corresponding author; e-mail: dvorskyd@vscht.cz strength and ultimate tensile yield strength are around 160 and $250 \mathrm{MPa}$, respectively. Elongation to fracture is between 4 and $7 \%[6,7]$.

Such properties are obtained by conventional casting and heat treatment. However, there are novel ways of materials fabrication such as powder metallurgy. It was proven that powder metallurgy provides materials with superior mechanical and corrosion properties [3]. Products prepared by powder metallurgy are characterized by fine-grained structure and with fine intermetallic phases if they are present. Products are usually made of atomized powders. Such powders are round shaped with fine grains. The composition of atomized powder is supersaturated solid solution due to high cooling rates [8].

The extrusion process is applied for compacting of the atomized powder. The extrusion process is based on extreme plastic deformation at high temperature which is associated with dynamic recrystallization. As a result, the final material has a fine-grained structure [4]. However, during the extrusion process, most magnesium alloys tend to form strong basal texture. This means that their basal planes are oriented parallel with the extrusion direction. Such grains are then more prone to the twinning mechanism of deformation. Twinning requires much less energy than the slip mechanism and it depends on the orientation of the grain with respect to the force applied (anisotropy of mechanical properties). However, an addition of RE elements can suppress the basal texture [9]. 
An alternative method of compacting powders is spark plasma sintering (SPS). This method is capable of the rapid increase of temperature (up to $1000^{\circ} \mathrm{C} / \mathrm{min}$ ), while the time of sintering is short (about $10 \mathrm{~min}$ ) by comparison with conventional sintering (about $5 \mathrm{~h}$ ). This is a great advantage for nanocrystalline powders as the grain growth is limited [4]. SPS is based on putting small pressure on the powder while the pulse of high current gets through the sample. The high current creates plasma between particles which helps to bound them together [10].

Magnesium alloys corrode very quickly depending strongly on the $\mathrm{pH}$ and on the concentration of chloride ions. Corrosion behavior limits their application unless it is used as a biodegradable material for implants like stents or screws [11]. Corrosion behavior is highly dependent on the structure of the material which is associated with the preparation process. WE43 alloy is known for its increased corrosion resistance as yttrium forms relatively stable corrosion products of $\mathrm{Y}_{2} \mathrm{O}_{3}$ and $\mathrm{Y}(\mathrm{OH})_{3}$ [12]. Intermetallic phases have also a great influence on corrosion properties. Most magnesium alloys have intermetallic phases with potential much higher than magnesium matrix. Intermetallic phases cause initial pitting near those phases because of micro-galvanic corrosion. The great advantage of the WE43 alloy is that all intermetallic phases present in the matrix have their potential close to magnesium matrix, eliminating the danger of microgalvanic corrosion [13].

\section{Experimental}

Samples were prepared from commercial WE43 atomized powder (mesh 300) and from commercial cast ingot. The powder was milled in ball planetary mill made of $\mathrm{ZrO}_{2}$ ceramic. Milling process was done under argon atmosphere for $16 \mathrm{~h}$. The rotation speed was $800 \mathrm{rpm}$ (rotation per minute) with changing the rotation direction every $30 \mathrm{~min}$. Atomized and milled powders were cold pressed in a die with diameter $19 \mathrm{~mm}$ with the force of $80 \mathrm{kN}$ for 5 min and then compacted by extrusion at $400{ }^{\circ} \mathrm{C}$ with extrusion ratio 10 and speed $5 \mathrm{~mm} / \mathrm{min}$. Alternatively, the atomized powder was prepared by SPS method at $500^{\circ} \mathrm{C}$ with heat rate $100^{\circ} \mathrm{C} / \mathrm{min}$ and $7 \mathrm{kN}$ pressure level and with the operation time of $30 \mathrm{~min}$. The SPS machine HP D 10 FCT system GmbH was used. The labeling of samples is described as follows:

- WE43-Ex prepared by extrusion at $400^{\circ} \mathrm{C}$ from the casted ingot;

- WE43-P +Ex prepared by extrusion at $400^{\circ} \mathrm{C}$ from atomized powder;

- WE43-M+Ex prepared by extrusion at $400^{\circ} \mathrm{C}$ from powder milled for $16 \mathrm{~h}$;

- WE43-SPS prepared by SPS method at $500^{\circ} \mathrm{C}$ from atomized powder.

\subsection{Microstructure}

Samples were ground on $\mathrm{SiC}$ grinding papers (P80$\mathrm{P} 4000$ ) and subsequently polished on diamond paste D3, D2, D0.7. The final polishing was done on Topol 2 with fine particles of $\mathrm{Al}_{2} \mathrm{O}_{3}$. Samples were etched in a solution containing $10 \mathrm{ml}$ of acetic acid, $4.2 \mathrm{~g}$ picric acid, $10 \mathrm{ml}$ distilled water and $70 \mathrm{ml}$ ethanol. The microstructure was studied by light microscope Olympus and by electron scanning microscope (SEM) TescanVEGA3 with energy dispersion spectrometry and electron backscattered diffraction (EBSD) detector (EDS, AZtec). Porosity was calculated by image analysis.

\subsection{Mechanical properties}

Compressive tests were measured on LabTest $5.250 \mathrm{SP} 1-\mathrm{VM}$ at room temperature on cylindrical samples with $6 \mathrm{~mm}$ in diameter and $8 \mathrm{~mm}$ in length. Constant deformation speed of $0.001 \mathrm{~s}^{-1}$ was used. Compressive yield strength (CYS), ultimate compressive strength (UCS) and total deformation were determined. Tensile yield strength (TYS), ultimate tensile strength (UTS) and total elongation were measured on the same machine at room temperature on samples with $3.5 \mathrm{~mm}$ in diameter in the constricted area and $25 \mathrm{~mm}$ in length. Constant deformation speed of $0.001 \mathrm{~s}^{-1}$ was used. The Vickers hardness (EN ISO 6507-1) measurements at loading corresponding to $1 \mathrm{~kg}$ were performed.

\subsection{Corrosion behavior}

Corrosion tests were carried out in simulated body fluid $(\mathrm{SBF})$. Samples were ground with $\mathrm{SiC}$ papers (P2500) and immersed in $\mathrm{SBF}$ at $37^{\circ} \mathrm{C}$ for two weeks. The ratio between the volume of $\mathrm{SBF}$ and area of the sample was $100 \mathrm{ml} / \mathrm{cm}^{2}$. Immersion tests were performed in closed containers in order to prevent evaporation of $\mathrm{SBF}$. After immersion, the corrosion products were removed in a solution of $200 \mathrm{~g} / \mathrm{l} \mathrm{CrO}_{3}, 10 \mathrm{~g} / 1 \mathrm{AgNO}_{3}$, and $20 \mathrm{~g} / \mathrm{l} \mathrm{Ba}\left(\mathrm{NO}_{3}\right)_{2}$. Corrosion rates were calculated from weight changes.

\section{Results and discussion}

\subsection{Structure}

Commercial atomized powder of WE43 alloy was used for the preparation of all materials except the one prepared from the cast ingot. As can be seen in Fig. 1, the particle size of atomized powder ranged from 50 to $200 \mu \mathrm{m}$. There is very fine dendritic structure inside each particle. It is composed of the $\alpha-\mathrm{Mg}$ solid solution and an interdendritic network of secondary phases containing increased amounts of alloying elements. This phase was identified by XRD as metastable $\beta 1$-phase with a composition close to $\beta$-phase [5], which was preferably formed during rapid cooling. The powder after milling was deformed; however, the dendritic structure was preserved. Nevertheless, the metastable phase vanished after milling and transformed into stable $\beta$-phase $\left(\mathrm{Mg}_{14} \mathrm{Nd}_{2} \mathrm{Y}\right)$ [14]. 

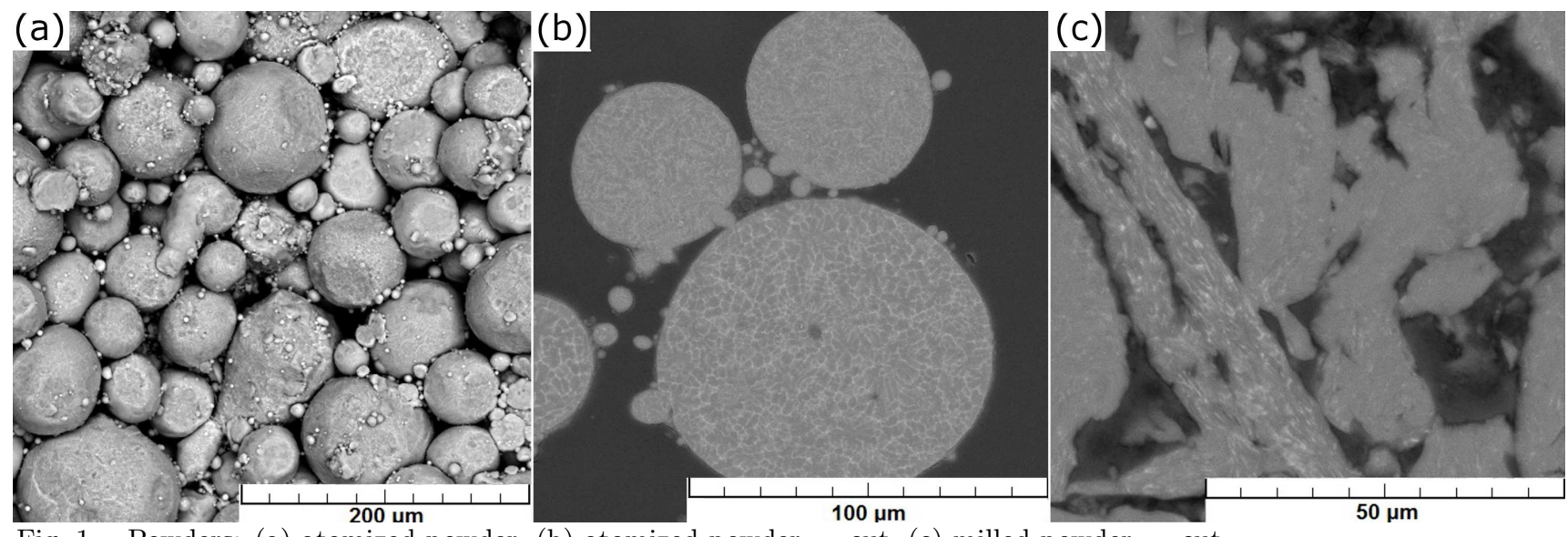

Fig. 1. Powders: (a) atomized powder,

(b) atomized powder -100 cut, (c) milled powder - cut.
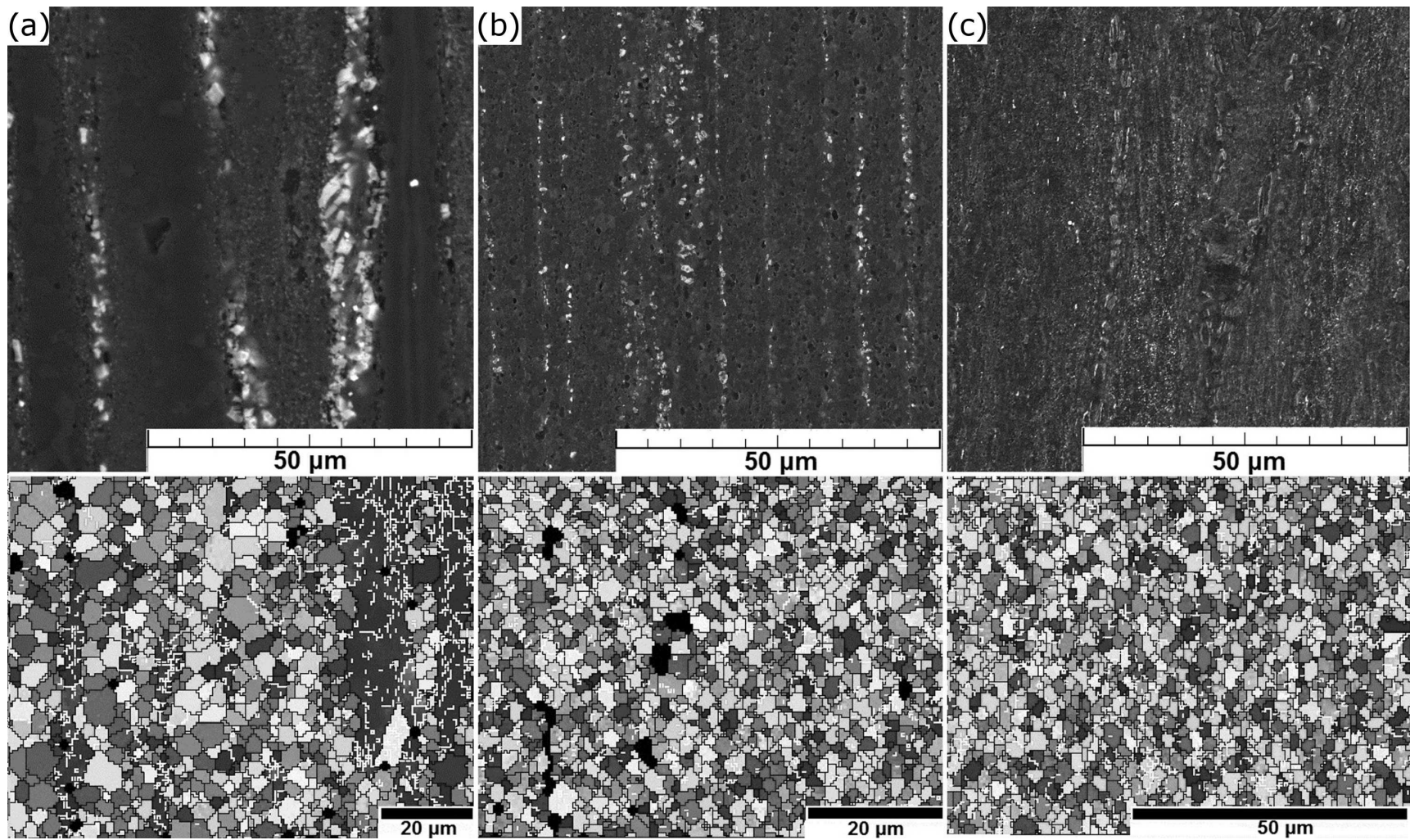

Fig. 2. Structures (SEM and EBSD): (a) WE43-Ex, (b) WE43-P+Ex, (c) WE43-M+Ex.

Extruded ingot contained intermetallic phases ordered in rows (Fig. 2a). These phases were relatively large, about $2 \mu \mathrm{m}$ in size and contained about $28 \mathrm{wt} \% \mathrm{Nd}$, 12 wt\% Y. Such composition corresponds to the equilibrium $\beta$ phase $\left(\mathrm{Mg}_{14} \mathrm{Nd}_{2} \mathrm{Y}\right)$ [14] as was confirmed by XRD analysis. Other phases were also observed in the structure. Yttrium rich phase which was blocked-shaped was identified as $\mathrm{Mg}_{24} \mathrm{Y}_{5}$. Neodymium rich phase was identified as $\mathrm{Mg}_{42} \mathrm{Nd}_{5}$. The solid solution between rows of phases contained $2 \mathrm{wt} \% \mathrm{Y}, 1 \mathrm{wt} \% \mathrm{Nd}$. The grain size of this material was between 0.5 and $4 \mu \mathrm{m}$. Moreover, there exist areas of deformed non-recrystallized grains. It is known that magnesium alloys form specific texture after deformation. Usually, the majority of grains have their basal planes oriented parallel with the extrusion direction. The same phenomenon was observed for this sample. However, RE elements are known to suppress formation of basal texture and substitute it with RE texture. Such effect has not been observed in this case. The reason for such behavior is connected with high extrusion temperature and low extrusion speed which contributed to the formation of basal texture [15].

The structure after extrusion of pressed atomized powder is in Fig. 2B. One can see intermetallic phases ordered in rows parallel with the extrusion direction, however, these phases are much finer compared to the phases in the extruded ingot. Furthermore, the phase composition is similar as in the case of the extruded ingot. The 
solid solution between rows of phases contained about $3.5 \mathrm{wt} \% \mathrm{Y}, 1.6 \mathrm{wt} \% \mathrm{Nd}$. This is a higher amount than in the case of the extruded ingot, which is associated with the higher concentration of alloying elements in the solid solution in atomized powder. As a consequence of the higher amount of alloying elements in solid solution, the volume fraction of secondary phases is decreased. The grain size ranged from 0.5 to $2 \mu \mathrm{m}$. Prepared material was fully recrystallized and it was characterized by only weak texture. Especially fine intermetallic phases that are homogeneously distributed in the matrix are responsible for such weak texture. These particles work as initiation sites for recrystallization process and prevent the grains from growing. As a result, a fine-grained structure with randomly oriented grains is prepared.

The extruded product prepared from milled powder was characterized by homogeneous microstructure with very fine intermetallic phases uniformly dispersed in the structure (Fig. 2c). These phases were identified as $\beta$ phase $\left(\mathrm{Mg}_{14} \mathrm{Nd}_{2} \mathrm{Y}\right), \mathrm{Mg}_{24} \mathrm{Y}_{5}$ and $\mathrm{Mg}_{42} \mathrm{Nd}_{5}$. The structure contained a higher amount of oxides which is probably caused by insufficiently pure argon atmosphere during milling. The amount of alloying elements in the solid solution was much higher than in previous samples ( $4.5 \mathrm{wt} \%$ Y, $2.4 \mathrm{wt} \% \mathrm{Nd}$ ). Those values are however overestimated due to fine intermetallic phases dispersed in the matrix. The milling process and subsequent extrusion did not lead to grain refinement as was presumed, but the grain size was more uniform as almost half of the grains were between 2 and $2.5 \mu \mathrm{m}$ in size. The texture of this material was very similar as in the case of the extruded product prepared from atomized powder.

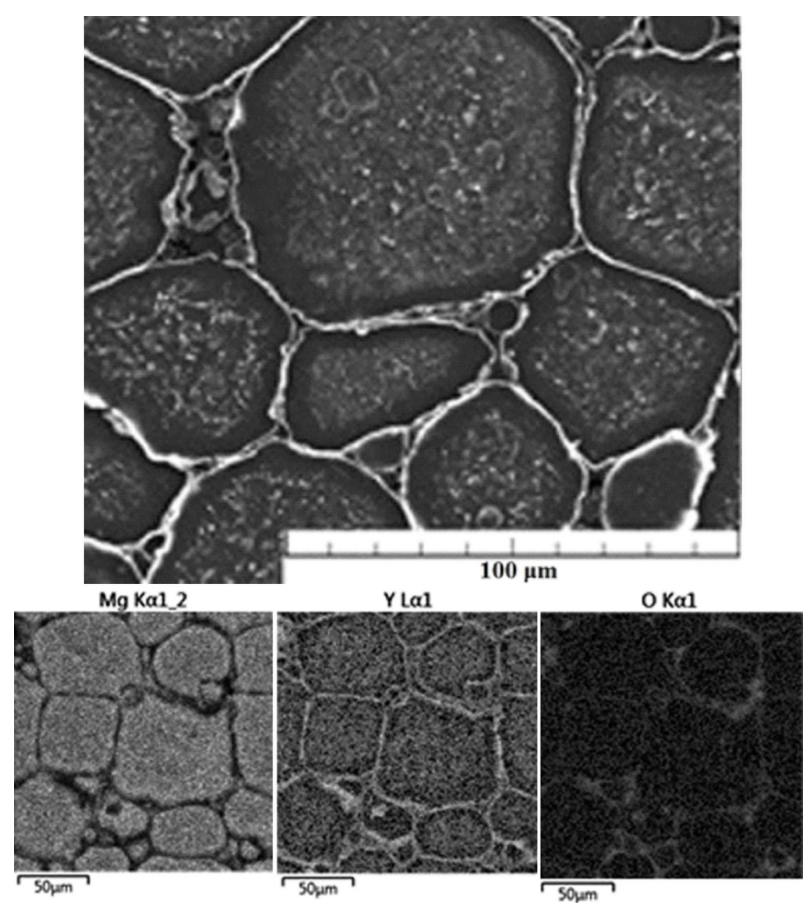

Fig. 3. Structure and element distribution in WE43SPS.
The sample prepared by spark plasma sintering is characterized with particles bordered with oxide shells rich on yttrium (Fig. 3), which diffused from the marginal areas of individual particles. This process makes the area below oxide shell poor in alloying elements. The porosity of prepared sample was below $0.5 \%$. The same very fine intermetallic phases were confirmed by XRD analysis $(\beta$ phase $\left(\mathrm{Mg}_{14} \mathrm{Nd}_{2} \mathrm{Y}\right), \mathrm{Mg}_{24} \mathrm{Y}_{5}$ and $\left.\mathrm{Mg}_{42} \mathrm{Nd}_{5}\right)$.

\subsection{Mechanical properties}

Compressive and tensile properties were measured. Material prepared by SPS method was only tested in compressive properties due to the size of the sample. CYS and UCS reached for such specimens about $190 \mathrm{MPa}$ and $355 \mathrm{MPa}$, respectively (Fig. 4). These values are relatively good considering the porosity and oxide shell presented in structure. Improved mechanical properties were obtained after extrusion. CYS and TYS are slightly higher for material prepared from atomized powder if compared with extruded ingot. Similarly the yield strengths of the extruded product from milled powder are higher than the yield strengths of extruded specimens prepared from atomized powder. On the other hand, the plasticity is reduced. The Hall-Petch relation is obeyed as the yield strength of the material is higher with smaller grain size. Another aspect is the solid solution hardening, because neodymium and yttrium are known to strongly strengthen the solid solution of magnesium alloys [16]. Another aspect affecting the mechanical properties of magnesium alloys is the texture of the material. This phenomenon causes the anisotropy of mechanical properties [9]. Material prepared from ingot was characterized with strong basal texture. Such orientation is favorable for twinning mechanism if the compressive strength is applied parallel to the extrusion direction. Therefore, the measured CYS is low. On the other hand, if the tensile force is applied parallel with the extrusion direction, the individual grains are oriented unfavorable for the twinning mechanism, and therefore, the measured TYS is higher. This explains the difference between CYS a TYS of the material prepared from ingot [17]. Other extruded materials exerted similar CYS and TYS values, because the texture of the material was very weak.

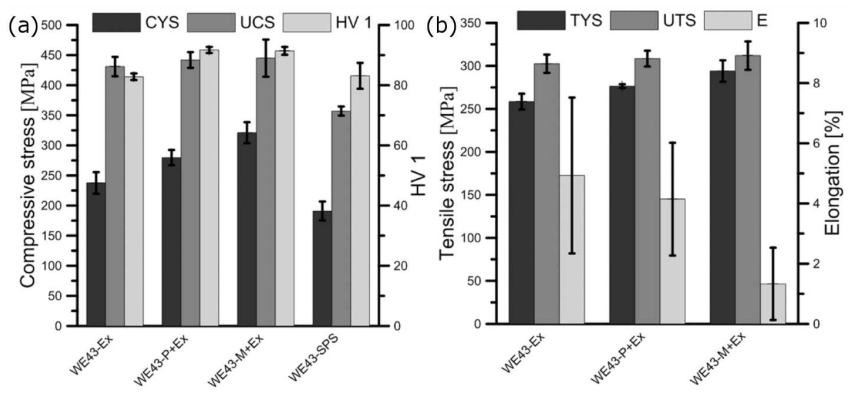

Fig. 4. Mechanical properties of the WE43 alloy prepared by different techniques: (a) compressive properties, (b) tensile properties. 


\subsection{Corrosion behavior}

WE43 alloy exerts increased corrosion resistance due to the formation of the stable corrosion products rich in yttrium [18]. The higher amount of alloying elements in the solid solution positively affects corrosion resistance [19]. Intermetallic phases present in the structure have their potential close to the magnesium matrix, so the danger of the galvanic corrosion is reduced. Figure 5 represents the corrosion rates of prepared samples in the simulated body fluid. Material prepared by SPS method exerts 4 times higher corrosion rate than extruded samples. Such behavior could be attributed to the structure of the material as the individual particles are surrounded by oxide shell and the material beneath is poor in the alloying elements. This makes the surroundings of interfaces between particles prone to corrosion. As the corrosion continues, individual particles fall off the sample and make the corrosion more rapid. Extruded materials exerted low corrosion rate which was below $0.4 \mathrm{mg} / \mathrm{cm}^{2} /$ day. A slight improvement can be seen in the case of material prepared by powder metallurgy. This is attributed to the finer structure with fine intermetallic phases as the corrosion is more uniform [20]. Also, the higher amount of alloying elements dissolved in the $\mathrm{Mg}$ matrix helped to build the layer of stable corrosion products like $\mathrm{Y}_{2} \mathrm{O}_{3}$ and partly $\mathrm{Y}(\mathrm{OH})_{3}[12]$.

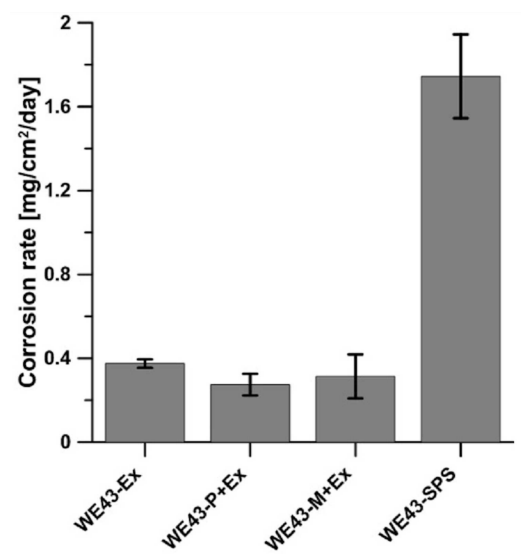

Fig. 5. Corrosion rates of the WE43 alloy prepared by different techniques.

\section{Conclusion}

In this paper, WE43 alloy was prepared by powder metallurgy methods and properties of products were subsequently compared with the material prepared by a standard technique including casting and extrusion. Results showed that materials prepared by powder metallurgy are characterized by slightly smaller grain size. Secondary phases of powder metallurgy products are very fine and the solid solution of $\alpha-\mathrm{Mg}$ is characterized by a higher concentration of alloying elements if compared to the product of a standard way of preparation. Moreover, finer structure resulted in a weak texture of the powder metallurgy products, and therefore, the low anisotropy of mechanical properties. Milling of the powder before compaction slightly improved mechanical properties of the final extruded product but also caused reduction of plasticity. Powder metallurgy products prepared by extrusion were characterized by increased corrosion resistance due to the finer structure and uniform corrosion. Spark plasma sintering was selected as the alternative method for the compacting of the powder. Sample exerts relatively good mechanical properties, but also high corrosion rate due to the depletion of some areas by alloying element, which are generally responsible for improved corrosion resistance.

\section{Acknowledgments}

We wish to thank for financial support to the Czech Science Foundation under the project No. GA16-08963S.

\section{References}

[1] C.-J. Li, H.-F. Sun, X.-W. Li, J.-L. Zhang, W.B. Fang, Z.-Y. Tan, J. Alloys Comp. 652, 122 (2015).

[2] M.P. Staiger, A.M. Pietak, J. Huadmai, G. Dias, Biomaterials 27, 1728 (2006).

[3] J. Kubásek, D. Dvorský, M. Čavojský, D. Vojtěch, N. Beronská, M. Fousová, J. Mater. Sci. Technol. 7, 33 (2017).

[4] D. Dvorsky, J. Kubasek, D. Vojtěch, F. Prusa, K. Nova, Manuf. Technol. 4, 16 (2016).

[5] J.F. Nie, B.C. Muddle, Acta Mater. 8, 48 (2000).

[6] K. Yu, W. Li, R. Wang, B. Wang, C. Li, Mater. Trans. 8, 49 (2008).

[7] F. Witte, N. Hort, C. Vogt, S. Cohen, K.U. Kainer, R. Willumeit, F. Feyerabend, Curr. Opin. Solid State Mater. Sci. 5, 12 (2008).

[8] D. Dvorsky, J. Kubasek, D. Vojtech, M. Cavojsky, Manuf. Technol. 5, 16 (2016).

[9] D. Dvorský, J. Kubásek, D. Vojtěch, I. Voňavková, M. Veselý, M. Čavojský, IOP Conf. Ser. Mater. Sci. Eng. 1, 179 (2017).

[10] F. Průša, D. Vojtěch, M. Bláhová, A. Michalcová T.F. Kubatík, J. Cížek, Mater. Des. 75, 65 (2015).

[11] G.L. Song, A. Atrens, Adv. Eng. Mater. 1, 1 (1999).

[12] M. Liu, P. Schmutz, P.J. Uggowitzer, G. Song, A. Atrens, Corros. Sci. 11, 52 (2010).

[13] H. Kalb, A. Rzany, B. Hensel, Corros. Sci. 57, 122 (2012).

[14] C. Antion, P. Donnadieu, F. Perrard, A. Deschamps, C. Tassin, A. Pisch, Acta Mater. 18, 51 (2003).

[15] N. Stanford, M.R. Barnett, Mater. Sci. Eng. A 1-2, 496 (2008).

[16] N. Stanford, R.K.W. Marceau, M.R. Barnett, Acta Mater. 82, 447 (2015).

[17] S. Kleiner, P.J. Uggowitzer, Mater. Sci. Eng. A 1, 379 (2004).

[18] P.-W. Chu, E.A. Marquis, Corros. Sci. 101, 94 (2015).

[19] J. Kubásek, D. Vojtěch, Trans. Nonferrous Met. Soc. China 5, 23 (2013).

[20] J. Liao, M. Hotta, Y. Mori, Mater. Sci. Eng. A 544 10 (2012). 